\title{
Optimalisasi Geometri Wedge pada Pesawat Teleterapi ${ }^{60} \mathrm{Co}$
}

\author{
Ajeng Sarinda Yunia Putri ${ }^{1}$, Suharyana ${ }^{2}$, Riyatun ${ }^{3}$, Muhtarom $^{4}$ \\ ${ }^{1,2,3}$ Group Riset Nuklir dan Radiasi, Prodi Fisika, FMIPA, Universitas Sebelas Maret \\ J1. Ir. Sutami No. 36A, Surakarta \\ ${ }^{4}$ Instalasi Radioterapi RSUD Dr. Moewardi, \\ J1. Kolonel Sutarto No. 132 Surakarta \\ Email : suharyana61@ @staff.uns.ac.id
}

\begin{abstract}
In RSUD Dr. Moewardi available wedge angle of $15^{\circ}, 30^{\circ}, 45^{\circ}$, and $60^{\circ}$. This research simulates with Monte Carlo N-Particle eXtended Version (MCNPX) computer software to determine the geometry of the wedge that produces the isodose angle of $20^{\circ}$, which is hoped to be applied to therapy of organ tilt of $20^{\circ}$ in some cases of cervical cancer. In simulation obtained the value of the wedge factor of isodose angle of $20^{\circ}$ and distribution of dose rate. The simulated material of wedge is Lead-Antimony Alloy. Verification of the simulation result was done by measuring the wedge factor of angle of $30^{\circ}$ and $60^{\circ}$, the simulation result was validated with result of measurement experiment on ${ }^{60}$ Co teletherapy in RSUD Dr. Moewardi Surakarta. The relative error between simulation and measurement experiment of wedge angle of $30^{\circ}$ is $8.84 \%$ and angle of $60^{\circ}$ is $4.35 \%$. The relative error is small to convince the researcher to develop a simulation at an isodose angle of about $20^{\circ}$. From the simulation results obtained isodose angle $20.3^{\circ}$ of Lead-Antimony Alloy material with geometry is length $16 \mathrm{~cm}$, width $14.9 \mathrm{~cm}$, thick $0.83 \mathrm{~cm}$, the value of the angle a of $3.2^{\circ}$. Wedge factor of isodose angle of $20.3^{\circ}$ is $(0.68 \pm 0.01)$. Wedge isodose angle of $20.3^{\circ}$ if used in therapy in an organ tilt about $20^{\circ}$ gives dose rate enough uniform.
\end{abstract}

Keywords : MCNPX, wedge factor, isodose, ${ }^{60}$ Co teletherapy

\begin{abstract}
Abstrak :. Di RSUD Dr. Moewardi tersedia wedge untuk sudut $15^{\circ}, 30^{\circ}, 45^{\circ}$, dan $60^{\circ}$. Penelitian ini mensimulasikan dengan software computer Monte Carlo N-Particle eXtended Version (MCNPX) untuk menentukan geometri wedge yang menghasilkan sudut isodosis $20^{\circ}$, dimana diharapkan dapat diaplikasikan pada terapi organ dengan kemiringan $20^{\circ}$ di beberapa kasus kanker serviks. Besaran yang diperoleh dari simulasi adalah nilai faktor transmisi wedge sudut isodosis $20^{\circ}$ dan distribusi laju dosis serap penggunaan wedge tersebut. Bahan wedge yang disimulasikan adalah Lead-Antimony Alloy. Verifikasi hasil simulasi dilakukan dengan pengukuran faktor wedge pada sudut isodosis $30^{\circ}$ dan $60^{\circ}$, hasil simulasi divalidasi dengan hasil pengukuran langsung pada pesawat teleterapi ${ }^{60} \mathrm{Co}$ di RSUD Dr. Moewardi Surakarta. Kesalahan antara simulasi dan pengukuran langsung pada isodosis sudut $30^{\circ}$ adalah $8,84 \%$ dan pada sudut $60^{\circ}$ adalah $4,35 \%$. Kesalahan relatif tersebut cukup kecil sehingga meyakinkan peneliti untuk menyusun simulasi pada sudut sekitar $20^{\circ}$. Dari hasil simulasi diperoleh isodosis sudut 20,3 $3^{\circ}$ dari bahan Lead-Antimony Alloy dengan geometri yaitu panjangnya 16 $\mathrm{cm}$, lebarnya $14,9 \mathrm{~cm}$, tebalnya $0,83 \mathrm{~cm}$, nilai sudut $\alpha$ sebesar $3,2^{\circ}$. Faktor wedge sudut $20,3^{\circ}$ sebesar $(0,68 \pm 0,01)$. Wedge sudut isodosis $20,3^{\circ}$ bila digunakan dalam terapi pada organ dengan kemiringan $20^{\circ}$ memberikan laju dosis yang cukup seragam.
\end{abstract}

Kata kunci : MCNPX, faktor wedge, isodosis, teleterapi ${ }^{60} \mathrm{Co}$

\section{PENDAHULUAN}

Radioterapi merupakan salah satu cara pengobatan kanker atau tumor menggunakan radiasi pengion untuk mematikan sel-sel kanker atau tumor tersebut (Wurdiyanto and Budiantari, 
2005). Pesawat ${ }^{60} \mathrm{Co}$ merupakan salah satu radioterapi eksternal (teleterapi) dengan sinar gamma $(\gamma)$ sebagai radiasi pengionnya (Azam et al., 2006).

Salah satu teknik penyinaran $\gamma$ pada organ dalam yang terkena kanker dengan permukaan miring ialah teknik penyinaran menggunakan filter wedge. Filter wedge terbuat dari bahan padat yang mempunyai daya serap tinggi terhadap radiasi pengion. Pada umumnya kanker atau tumor yang letaknya di dalam tubuh memiliki kedalaman yang berbeda-beda dan bentuknya tidak teratur. Wedge berguna untuk membentuk profil distribusi dosis di kedalaman referensi sesuai yang diinginkan agar dosis pada sel kanker homogen (Azam et al., 2006).

Pemakaian wedge dapat menurunkan dosis serap karena proses atenuasi sinar $\gamma$ oleh bahan wedge :

$$
I_{(x)}=I_{0} e^{-\mu x}
$$

\section{Keterangan :}

$$
\begin{array}{ll}
I_{(x)} & =\text { intensitas radiasi setelah } \\
& \text { melewati bahan }\left(\mathrm{J} \mathrm{m}^{-2} \mathrm{~s}^{-1}\right) \\
I_{0} & =\text { intensitas radiasi sebelum } \\
& \text { melewati bahan }\left(\mathrm{J} \mathrm{m}^{-2} \mathrm{~s}^{-1}\right) \\
\mu & =\text { koefisien serapan linear }\left(\mathrm{m}^{-1}\right) \\
x & =\text { ketebalan bahan }(\mathrm{m})
\end{array}
$$

Faktor transmisi wedge (untuk sederhananya disebut faktor wedge) merupakan rasio dosis serap penyinaran menggunakan wedge dan tanpa menggunakan wedge di suatu titik di pusat berkas radiasi (Khan, 2003). Nilai faktor wedge dapat digunakan untuk memperkirakan laju dosis serap yang diterima pasien pada saat penyinaran menggunakan bantuan wedge.

Saat ini, pada unit teleterapi ${ }^{60} \mathrm{Co}$ di RSUD Dr. Moewardi sudut isodosis wedge yang tersedia hanya $15^{\circ}, 30^{\circ}, 45^{\circ}$, dan $60^{\circ}$. Sudut isodosis wedge $(\theta)$ ialah sudut yang terbentuk antara kurva isodosis dengan garis normal pusat berkas sinar pada kedalamaan tertentu. Kurva isodosis merupakan kurva yang menghubungkan nilai dosis yang sama sebagai fungsi kedalaman dan jarak melintang dari pusat berkas. Kemiringan organ pada kanker serviks ada yang mendekati $20^{\circ}$, sehingga perlu dilakukan simulasi untuk mendapatkan wedge sudut isodosis $20^{\circ}$.

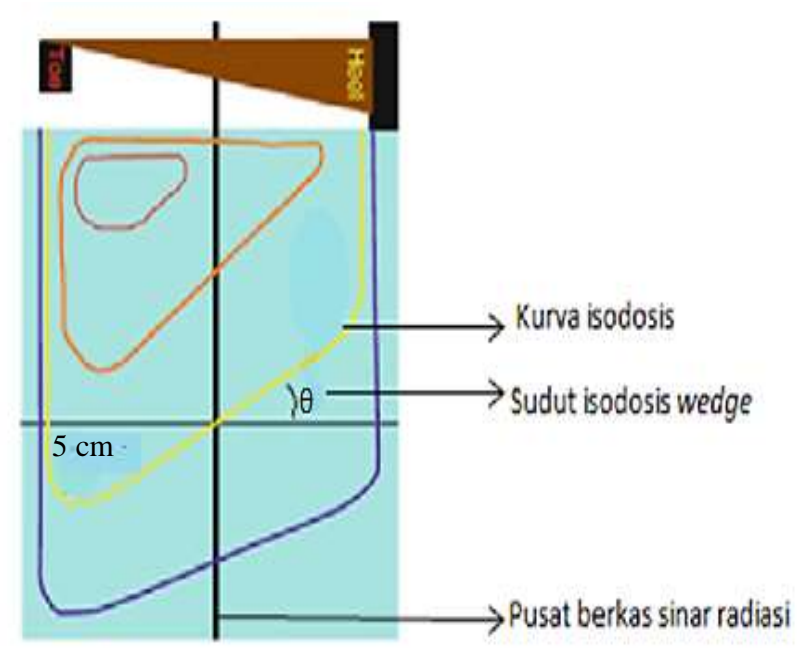

Gambar 1. Wedge dan Kurva Isodosis (Chang et al., 2014) 
Simulasi perhitungan laju dosis serap dapat dilakukan menggunakan Monte Carlo NPartikel (MCNP), software komputer berbasis metode Monte Carlo. Software MCNP digunakan untuk menyimulasikan perjalanan partikel neutron, elektron dan foton dalam suatu material tiga dimensi (Shultis and Faw, 2011).

\section{METODE PENELITIAN}

Perhitungan laju dosis serap dilakukan dengan menggunakan dua metode yaitu metode pengukuran langsung dan metode simulasi. Verifikasi hasil simulasi dilakukan dengan menghitung faktor wedge pada sudut isodosis $30^{\circ}$ dan $60^{\circ}$, hasil simulasi divalidasi dengan hasil pengukuran langsung pada pesawat ${ }^{60} \mathrm{Co}$ di RSUD Dr. Moewardi.

Pengukuran langsung laju dosis serap mengacu pada Technical Reports Series (TRS)-398 yang dikeluarkan oleh International Atomic Energy Agency (IAEA). Simulasi perhitungan laju dosis serap dilakukan menggunakan MCNP. Setelah didapatkan laju dosis serap tanpa wedge dan laju dosis serap menggunakan wedge, dihitung faktor wedge:

$$
\text { faktor wedge }=\frac{\text { dosis serap menggunakan wedge }}{\text { dosis serap tanpa menggunakan wedge }}
$$

\section{HASIL DAN PEMBAHASAN}

Tampilan 3 dimensi simulasi dengan MNCPX dapat dilihat pada Gambar 2. Laju dosis pada kedalaman $5 \mathrm{~cm}$ di pusat berkas sinar hasil pengukuran langsung dan hasil simulasi dapat dilihat pada Tabel 1.Setelah diperoleh laju dosis serap, kemudian dihitung besarnya faktor wedge, yang disajikan pada Tabel 2 .

Tabel 1. Laju Dosis Serap pada Kedalaman $5 \mathrm{~cm}$

\begin{tabular}{cccc}
\hline Pengukuran & $\begin{array}{c}\text { Hasil Pengukuran } \\
\text { Langsung }(\mathrm{mGy} / \mathrm{s})\end{array}$ & $\begin{array}{c}\text { Hasil Simulasi } \\
(\mathrm{mGy} / \mathrm{s})\end{array}$ & $\begin{array}{c}\text { Kesalahan } \\
\text { Relatif }(\%)\end{array}$ \\
\hline $\begin{array}{c}\text { Tanpa wedge } \\
\text { Dengan wedge sudut }\end{array}$ & $16,95 \pm 0,007$ & $16,95 \pm 0,08$ & - \\
$30^{\circ}$ & $9,34 \pm 0,005$ & $10,10 \pm 0,1$ & 8,11 \\
$\begin{array}{c}\text { Dengan wedge sudut } \\
60^{\circ}\end{array}$ & $8,02 \pm 0,003$ & $7,60 \pm 0,1$ & 5,22 \\
\hline
\end{tabular}

Tabel 2. Faktor Wedge

\begin{tabular}{cccc}
\hline Sudut Wedge & Pengukuran Langsung & Hasil Simulasi & $\begin{array}{c}\text { Kesalahan } \\
\text { Relatif }(\%)\end{array}$ \\
\hline $30^{\circ}$ & $0,55 \pm 0,0003$ & $0,59 \pm 0,02$ & 8,84 \\
$60^{\circ}$ & $0,47 \pm 0,0002$ & $0,45 \pm 0,01$ & 4,35 \\
\hline
\end{tabular}

Kesalahan relatif dari faktor wedge sudut isodosis $30^{\circ}$ dan sudut isodosis $60^{\circ}$ di bawah $10 \%$ dan penulis menganggap hasil ini baik. Selanjutnya dilakukan simulasi untuk mencari geometri wedge yang menghasilkan sudut isodosis sekitar $20^{\circ}$. Penulis mencoba berbagai 
ukuran geometri hingga diperoleh geometri yang optimal, yaitu didapatkan sudut isodosis $(\theta)$ sebesar $20,3^{\circ}$.

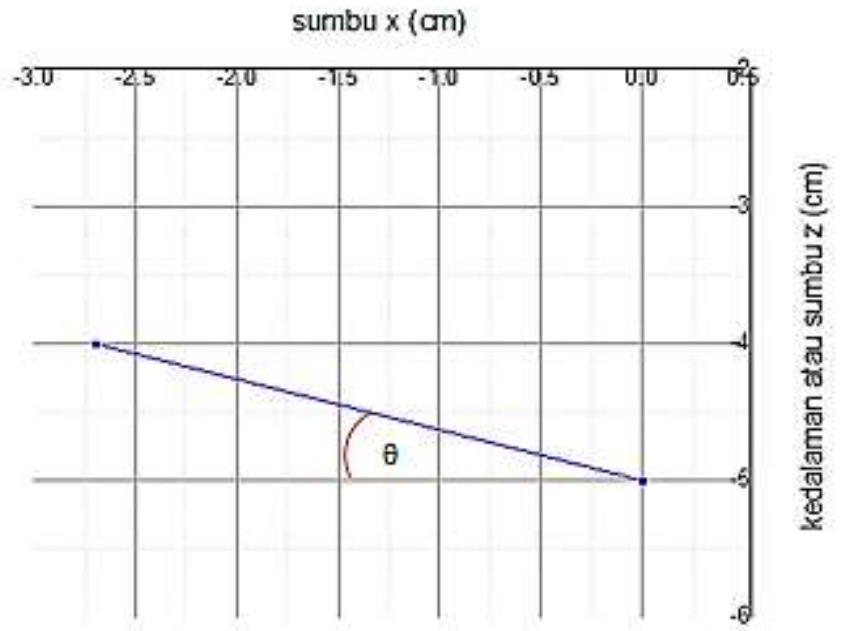

Gambar 2. Kurva Isodosis Wedge dan Sudut Isodosis Wedge

Optimasi simulasi geometri wedge memperoleh sudut $20,3^{\circ}$ yang isodosis pada kedalaman $5 \mathrm{~cm}$. Geometri wedge ini terdiri dari geometri panjang $16 \mathrm{~cm}$, lebar $14,9 \mathrm{~cm}$, tebal $0,83 \mathrm{~cm}$, dan nilai sudut $\alpha$ sebesar 3,2 ${ }^{\circ}$ Geometri wedge dapat dilihat pada Gambar 3 .

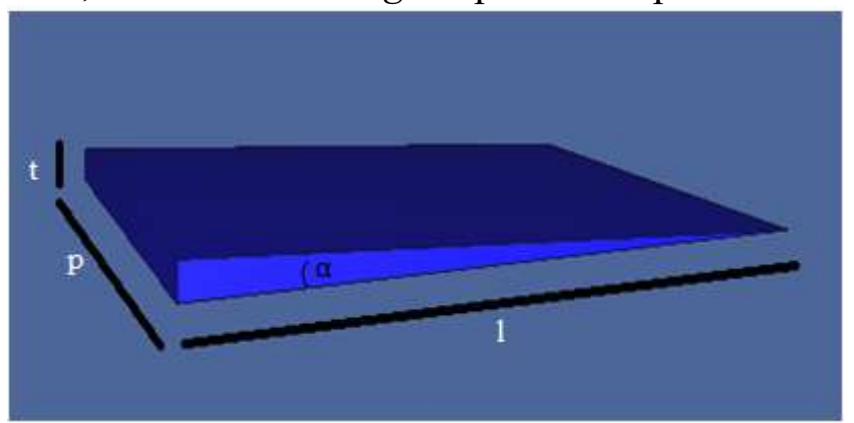

Gambar 3. Geometri Wedge Isodosis Sudut Isodosis $20,3^{\circ}$

Nilai faktor wedge sudut isodosis $20,3^{\circ}$ sebesar $0,68 \pm 0,01$ artinya laju dosis serap yang ditransmisikan sudut isodosis wedge $20,3^{\circ}$ di pusat berkas sebesar $68 \%$ dari laju dosis serap tanpa menggunakan wedge.

Selanjutnya dilakukan simulasi penyinaran dengan menggunakan wedge sudut isodosis $20,3^{\circ}$ pada organ yang kemiringannya $20^{\circ}$, tampilan 2 dimensi dari simulasi ini ditunjukkan Gambar 4. Pada kanker serviks misalnya, permukaan organnya miring tetapi diperlukan profil kurva isodosis yang datar di kedalaman tertentu. Energi radiasi $\gamma$ sumber ${ }^{60} \mathrm{Co}$ efektif membunuh sel kanker yaitu pada kedalaman 10 kurang dari $\mathrm{cm}$. 


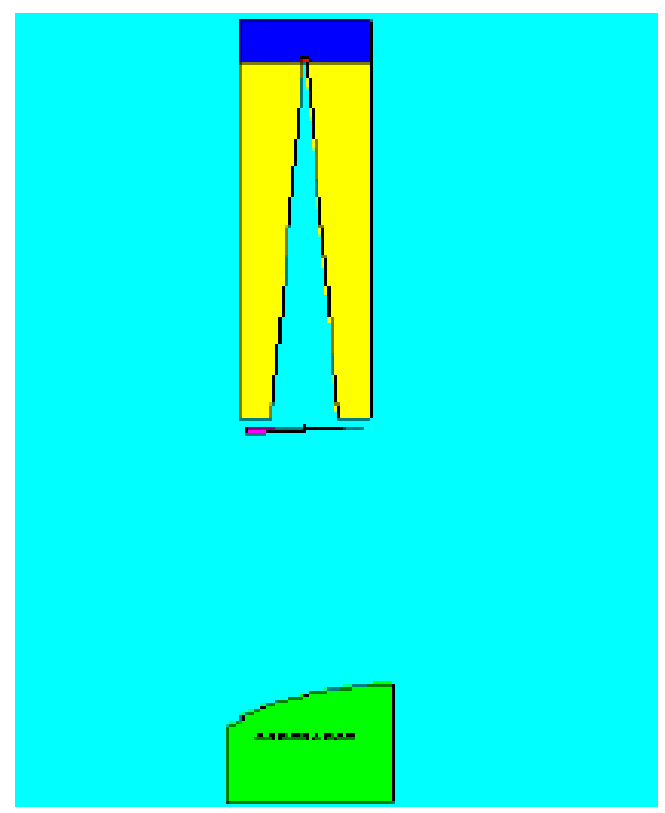

Gambar 4. Tampilan 2 Dimensi

Setelah dilakukan simulasi penyinaran dengan wedge sudut isodosis $20,3^{\circ}$ pada organ yang kemiringannya $20^{\circ}$ didapatkan distribusi laju dosis pada kedalaman $5 \mathrm{~cm}$ sampai $9 \mathrm{~cm}$. Distribusi tersebut ditunjukkan pada Gambar 5.

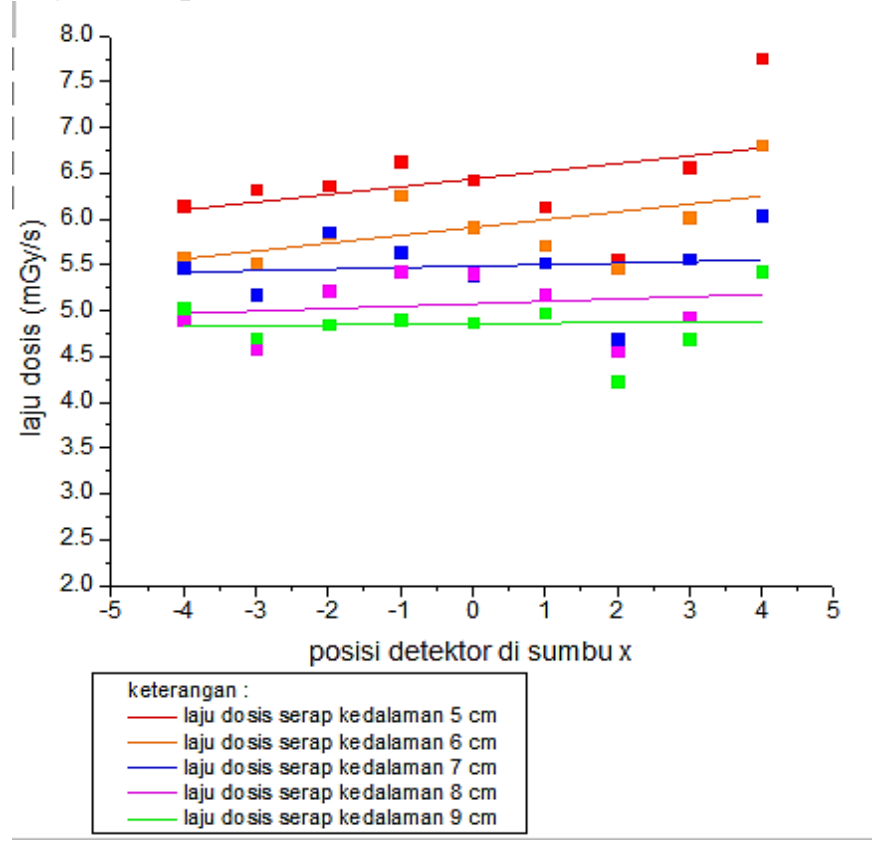

Gambar 5. Distribusi Laju Dosis pada Kedalaman $5 \mathrm{~cm} \mathrm{-9} \mathrm{cm}$

Distribusi laju dosis pada kedalaman $5 \mathrm{~cm}$ sampai $9 \mathrm{~cm}$ ditinjau dari standart deviasi data yang diperoleh pada posisi detektor diperlihatkan pada Tabel 3. Laju dosis hasil dari wedge $20,3^{\circ}$ menunjukkan isodosis yang cukup baik, variasi terbesar adalah $8,54 \%$. Semakin dalam jaringan akan memperoleh dosis yang makin seragam 
Tabel 3. Nilai Laju Dosis Serap Rata-Rata di setiap Kedalaman Jaringan

\begin{tabular}{cccc}
\hline $\begin{array}{c}\text { Kedalaman } \\
(\mathrm{cm})\end{array}$ & $\begin{array}{c}\text { Laju Dosis } \\
\text { Rata-rata } \\
(\mathrm{mGy} / \mathrm{s})\end{array}$ & $\begin{array}{c}\text { Standar } \\
\text { Deviasi } \\
(\mathrm{mGy} / \mathrm{s})\end{array}$ & $\begin{array}{c}\text { Variasi } \\
(\%)\end{array}$ \\
\hline 5 & 6,44 & 0,55 & 8,54 \\
6 & 5,91 & 0,40 & 6,77 \\
7 & 5,48 & 0,37 & 6,75 \\
8 & 5,07 & 0,32 & 6,31 \\
9 & 4,86 & 0,30 & 6,17 \\
\hline
\end{tabular}

\section{KESIMPULAN}

Simulasi wedge pada pesawat ${ }^{60} \mathrm{Co}$ ini cukup berhasil, dengan kesalahan relative yang kecil dibandingkan hasil pengukuran. Simulasi menghasilkan wedge isodosis $20,3^{\circ}$ dari bahan Lead-Antimony Alloy dengan geometri yaitu panjang $16 \mathrm{~cm}$, lebar $14,9 \mathrm{~cm}$, tebal 0,83 $\mathrm{cm}$, dan nilai sudut $\alpha$ sebesar $3,2^{\circ}$. Faktor wedge sudut isodosis $20,3^{\circ}$ sebesar $0,68 \pm 0,01$ serta memberikan laju dosis yang cukup seragam di kedalaman organ $5-9 \mathrm{~cm}$.

\section{DAFTAR PUSTAKA}

Azam, M., Sofjan Firdausi, K., \& Silvani, S. (2006). Penentuan Karakterisasi Cerrobend Sebagai "Wedge Filter" Pada Pesawat Teleterapi ${ }^{60}$ Co. Berkala Fisika, 9(3), 131135.

Wurdiyanto, G., \& Budiantari, C.T. (2005). Optimasi Aspek Keselamatan Pada Kalibrasi Pesawat Radioterapi.Buletin Alara,7,11-16.

Khan, F.M. (2003). The Physics Of Radiation Therapy. USA: LIPPINCOTT WILLIAMS \& WILKINS.

Chang, D.S., Lasley, F.D., Das, I.J., Mendonca, M.S., \& Dynlacht, J.R. (2014). Basic Radiotherapy Physics and Biology. London: Springer.

Shultis, J. K. \& Faw, R.E. (2011). An MCNP Primer. Manhattan : Kansas State University. 